\title{
Epigenetic effects of stress and corticosteroids in the brain
}

\section{Richard G. Hunter*}

Laboratories of Neuroendocrinology and Neurobiology and Behavior, The Rockefeller University, New York, NY, USA

\section{Edited by:}

Nicola Maggio, The Chaim Sheba

Medical Center, Israel

Reviewed by:

Menahem Segal, Weizman Institute

for Science, Israel

Nicola Maggio, The Chaim Sheba

Medical Center, Israel

${ }^{*}$ Correspondence:

Richard G. Hunter, Laboratories of Neuroendocrinology and

Neurobiology and Behavior, The Rockefeller University, 1230 York

Ave., New York, NY 10065, USA.

e-mail: rhunter@rockefeller.edu
Stress is a common life event with potentially long lasting effects on health and behavior. Stress, and the corticosteroid hormones that mediate many of its effects, are well known for their ability to alter brain function and plasticity. While genetic susceptibility may influence the impact of stress on the brain, it does not provide us with a complete understanding of the capacity of stress to produce long lasting perturbations on the brain and behavior. The growing science of epigenetics, however, shows great promise of deepening our understanding of the persistent impacts of stress and corticosteroids on health and disease. Epigenetics, broadly defined, refers to influences on phenotype operating above the level of the genetic code itself. At the molecular level, epigenetic events belong to three major classes: DNA methylation, covalent histone modification and non-coding RNA. This review will examine the bi-directional interactions between stress and corticosteroids and epigenetic mechanisms in the brain and how the novel insights, gleaned from recent research in neuro-epigenetics, change our understanding of mammalian brain function and human disease states.

Keywords: epigenetics, stress, corticosteroids, glucocorticoid receptor, brain development

\section{INTRODUCTION}

Epigenetics, in the sense the term was originally coined by Waddington (Waddington, 1942), referred to the "interactions between genes and their products which bring the phenotype into being." Like the concept of the gene itself, much has changed with regard to epigenetics since the 1940s. At present the term refers to molecular or cellular alterations, which influence gene expression, and by extension physiology and behavior, without causing alterations to the DNA sequence itself. These alterations are generally construed to include DNA methylation, non-coding RNAs and covalent histone modifications or "marks," which include acetylation, phosphorylation, methylation, ubiquitination, and a growing host of ever more exotic moieties. These marks are written by a variety of enzymes, which interact in complex ways to alter chromatin structure and the availability of the underlying DNA for interactions with the transcriptional machinery. Epigenetic mechanisms, unlike those of the relatively static genome, are more dynamic, tissue specific and significantly from the perspective of disease, potentially reversible.

Epigenetic processes are active in the brain and have been linked to an increasing number of brain disorders such as Fragile X and Rett syndromes, Huntington's disease, drug abuse, schizophrenia and affective disorders (Jiang et al., 2008). Epigenetic modifications have long been thought to be involved in learning and memory, e.g., (Schmitt and Matthies, 1979), but only in the past few years have the mechanisms begun to be outlined in detail. It has also become apparent that both corticosteroids and stress have a pronounced epigenetic impact in both humans and animal models and that the relationship between the stress response and epigenetics in the brain is bidirectional. In keeping with Waddington's developmental definition of epigenetics, it is also apparent that stress and epigenetics interact selectively at a number of important neuro-developmental critical periods to influence brain and behavior not only across individual life spans but across generations as well.

\section{EPIGENETIC MECHANISMS DNA MODIFICATIONS}

DNA methylation of cytosines adjacent guanines (CpG sites) is a major epigenetic mark. CpG islands, which are regions of the genome with a high concentration of $\mathrm{CpG}$ pairs are often located within the promoter or enhancer regions of genes. Cytosine methylation is typically a silencing mark, thus increased methylation of promoter $\mathrm{CpG}$ islands often reduces gene expression, while hypomethylation is usually associated with increased expression (Illingworth and Bird, 2009). DNA methylation is established developmentally, typically via DNMT3a and b and maintained throughout the lifespan of a cell, often by DNMT1. Demethylation is less well described, but it is clear that it occurs, often quite dynamically in the brain and elsewhere. It is worth noting here that the glucocorticoid receptor (GR) is known to regulate local methylation around the glucocorticoid response elements where it binds DNA (Turner et al., 2010) (see Figure 1). Other cytosine modifications, such as hydroxymethylation, have recently been observed in brain tissues (Kriaucionis and Heintz, 2009; Wu and Zhang, 2011) and there is evidence that the Ten-eleven translocation (TET) proteins, which act on methylcytosine to produce hydroxymethylcytosine, may be part of the de-methylation pathway, though their activity in brain and their epigenetic significance remain unclear.

\section{HISTONE MODIFICATIONS}

Histone proteins package DNA into chromatin, which may be either tightly packed and transcriptionally silent heterochromatin, or more open and actively transcribed euchromatin. The four core histone proteins, $\mathrm{H} 2 \mathrm{~A}, \mathrm{H} 2 \mathrm{~B}, \mathrm{H} 3$, and $\mathrm{H} 4$ form octomers 


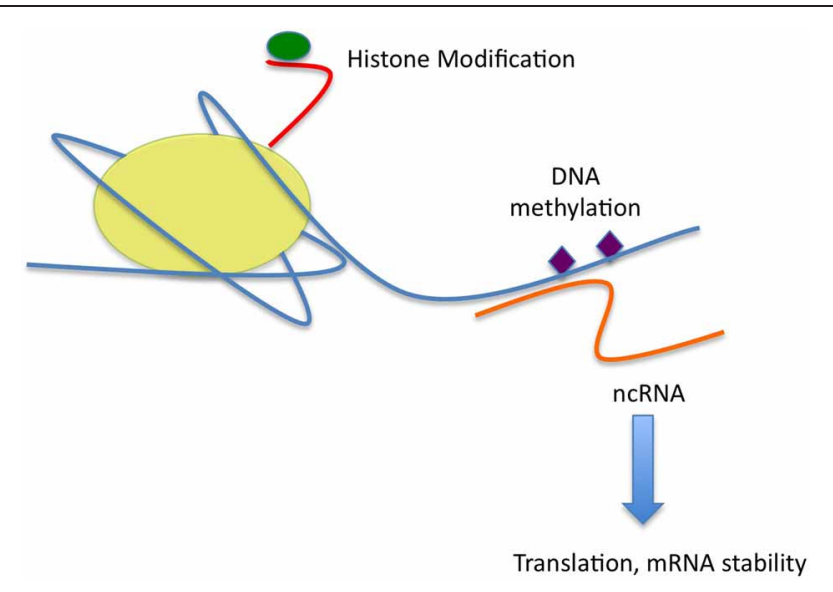

FIGURE 1 | Figure one is a representation of the effects of stress on the three main epigenetic mechanisms as presently understood. Stress may act to alter modifications (green) of the tails (red) of the core histone proteins of the nucleosome (yellow). Some modifications, such as acetylation, or histone 3K4 trimethylation, are associated with a loose, euchromatic state and active gene transcription. Others, such as Histone H3K9 or K27 trimethylation, are associated with dense heterochromatin and gene silencing or repressed transcription. DNA methylation (purple) is commonly associated with transcriptional repression, the function of more exotic DNA modifications, such as cytosine hydroxymethylation is a subject of intense interest, but as yet unresolved. Non-coding RNA species (orange), such as microRNAs, may alter gene transcription as well, but have effects post-transcriptionally on both mRNA stability and translation into protein.

around which DNA is wrapped. Each of the core histones has a relatively unstructured $\mathrm{N}$-terminal tail which may be covalently modified at a number of residues (while the tail is the focus of much work on histone modification it should be said that covalent modifications of core of the protein are possible) (see Figure 1). The number of described histone modifications or "marks" is quite large (Allis et al., 2007), but thus far those which have been subject to the most examination at the level of the nervous system are histone acetylation, methylation and phosphorylation. Acetylation of histones is typically associated with a transcriptionally active state. Acetylation of histone lysine residues is achieved by histone acetyl-transferases or HATs, and the mark is erased by histone de-acetylases or HDACs. HATs and HDACs are relatively non-specific as to the specific residue they modify relative to the histone methyltransferases (HMTs) and histone de-methylases (HDMs), which tend to be both residue and valence specific. Histones lysine and arginine residues, the later may be mono- di- or tri-methylated, while the former may be mono- or di-methylated (Allis et al., 2007; Kouzarides, 2007). Each valence may be associated with a different functional state in the local chromatin, e.g., trimethylation of histone H3 lysine 4 (H3K4me3) is often associated with active gene expression, H4K20me1 is also associated with active gene expression but $\mathrm{H} 4 \mathrm{~K} 20 \mathrm{me} 3$ is associated with silencing, as are $\mathrm{H} 3 \mathrm{~K} 9 \mathrm{me} 3$ and H3K27me3 (Kouzarides, 2007; Ruthenburg et al., 2007a; Balakrishnan and Milavetz, 2010). Phosphorylation of histones, most often at serine residues, is controlled by a number of kinases and phosphatases, which are often involved in other cellular processes as well. Histone phosphorylations are associated with transcriptional regulation, mitotic check points and DNA damage, as well as cross talk with other histone marks (Banerjee and Chakravarti, 2011). Though histone marks were initially envisioned to comprise a relatively simple code (Jenuwein and Allis, 2001), it is apparent now that the combinatorial state of histone marks on a histone tail may be as, or more, important than the contributions of any one mark (Ruthenburg et al., 2007b).

\section{NON-CODING RNA}

Non-coding or ncRNA is another contributor to the stock of epigenetic mechanisms that may be at play in the brain. A variety of different functional types of RNA fall under the rubric of ncRNA, the best known being microRNAs (miRNA), which regulate mRNA levels by a variety of means (see Figure 1). Of course, there are a variety of other short ncRNA species and long non-coding RNA (lncRNA, ncRNA longer than 200 bases), which plays a number of roles in regulating gene activity and chromatin structure as well. To date miRNAs are best established as epigenetic factors in the nervous system. However, both lncRNAs and snoRNAs, which are involved in the processing of ribosomal RNA, have been implicated in disorders such as Alzheimer's disease and Prader-Willi syndrome (Esteller, 2011) and it is likely that novel species of ncRNA will be linked to nervous system function and dysfunction with greater and greater frequency in coming years, as they have in cancer research, which historically, has been closer to the leading edge of epigenetics than the neurosciences.

\section{EPIGENETIC EFFECTS STRESS AND CORTICOSTEROIDS IN DEVELOPMENT}

It has been known for some time that stressful manipulations in early life contribute to changes in stress reactivity that persist into adulthood. More severe interventions like maternal separation (MS) having a sensitizing effect on the stress axis and milder ones such as neonatal handling promoting a more resilient phenotype (Francis and Meaney, 1999). Many of these manipulations alter the expression of the GR or other stress responsive genes such as AVP, CRH or BDNF. One of the most interesting examples of the contribution of early environment to epigenetic alterations in stress responsiveness is the effect of natural variations in maternal nursing, licking and grooming behavior on the behavioral and endocrine responses to stress in adult offspring described in a series of papers produced in collaboration between the Meaney and Szyf labs at McGill University. Meaney established that variations in arch backed nursing $(\mathrm{ABN})$ and licking and grooming (LG) were stable within individual mothers and that these correlated with behavioral differences in their adult offspring (Champagne et al., 2003). Further, they demonstrated that high LG-ABN mothers produced offspring with higher hippocampal GR and lower levels of hypothalamic CRH and consequently lower HPA activation in response to stress (Liu et al., 1997; Francis et al., 1999). Remarkably, these effects persisted across generations in a non-genomic fashion, prompting some to wonder if a partial rehabilitation of Lamarck was in order.

The mechanism by which these epigenetic effects were transmitted was first described in detail in a paper by Weaver (Weaver et al., 2004). He found that the adult offspring of low LG-ABN 
mothers showed higher levels of DNA methylation of the GR 1-7 promoter (corresponding to the human 1-F promoter) (Turner and Muller, 2005) in the hippocampus than those of High LG$\mathrm{ABN}$ mothers. Cross fostering of pups to high LG-ABN dams was found to reverse the change in the methylation of this region, demonstrating that the epigenetic change was responsive to maternal input. The methylation was most strongly targeted to the NGFI-A (also known as egr 1) response element within the GR 1-7 promoter, and chromatin immunoprecipitation (ChIP) studies in 6 day old pups revealed lower NGFI-A binding in this region in low $\mathrm{LG}-\mathrm{ABN}$ pups than in high, and this difference does persist into adulthood, though hippocampal levels of NGFI-A are the same. In addition to lower DNA methylation, high LG$\mathrm{ABN}$ offspring showed higher levels of histone acetylation at the GR 1-7 promoter suggesting that there is a persistent epigenetic marking of this locus during the neonatal critical period (Weaver et al., 2004, 2007). As histone de-acetylase inhibitors (HDACi) can both increase histone acetylation and reduce DNA methylation (Cervoni and Szyf, 2001), Weaver infused the HDACi trichostatin A into the brains of adult rats and successfully reversed both the deficits in hippocampal GR expression and HPA stress reactivity found in low maternal LG-ABN animals (Weaver et al., 2004), thus demonstrating for the first time the potential reversibility of the epigenetic consequences of stress. Provocatively, McGowan and collaborators found that similar alterations occurred in suicides with a history of childhood abuse (McGowan et al., 2009), though other groups have failed to replicate this finding in major depressives (Alt et al., 2010) it remains highly interesting.

The MS model of early life stress, where pups are separated from their dam for several hours a day during the first two weeks of life, has also been demonstrated to have an epigenetic impact. MS, like low LG-ABN rearing, produces HPA hyperactivity in adults, partly by increasing expression of the adrenocorticotrophin (ACTH) gene, pomc, in the anterior pituitary. As ACTH release is driven by the release of AVP and $\mathrm{CRH}$ from the hypothalamus into the pituitary portal circulation, Murgatroyd and collaborators examined the effect of MS on AVP and CRH gene expression. They found that MS increased AVP, but not CRH expression in the hypothalamus, and that the increase was associated with DNA hypomethylation in an AVP enhancer region which appears to be the major binding site for the methyl CpG-binding domain protein MeCP2 (Murgatroyd et al., 2009). Notably, MeCP2 is also associated with the primary pathology of Rett syndrome (Kriaucionis and Bird, 2003), and to play a role in the regulation of the expression of stress responsive genes such as BDNF (Chen et al., 2003; Martinowich et al., 2003). It has also been demonstrated that MS, like the LG-ABN model can produce transgenerational epigenetic effects, though, in contrast to the later model, some of the changes in DNA methylation appear to be passed on in the male germ line (Franklin et al., 2010). Another early life stress model, using stressed and abusive dams, showed that the pups reared under these conditions showed reduced levels of BDNF expression in the prefrontal cortex, which correlated with DNA hypermethylation at the activity dependent exon IV promoter. The investigators were able to reverse this effect by infusing the DNA methylation inhibitor zebularine (Roth et al., 2009).
Prenatal stress exposure also has an impact on stress reactivity in adulthood. Chronic exposures produce exaggerated corticosterone responses to stress and a number of deficits in hippocampal structure and function (Fujioka et al., 1999; Lemaire et al., 2000; Coe et al., 2003), while milder exposures produce a more resilient phenotype, resembling neonatal handling (Fujioka et al., 2001, 2006). Mueller and Bale have recently shown that prenatal stress results in increased DNA methylation at the GR 1-7 promoter in the hippocampus and reduced methylation at the $\mathrm{CRH}$ promoter in the hypothalamus and central amygdala of adult male animals with corresponding alterations in gene expression. Similar changes were not observed in females, and the sex difference correlates with differences in the expression of a number of genes in the placenta, including the DNA methyltransferases DNMT1 (Mueller and Bale, 2008). Some of the epigenetic effects of prenatal stress in this model were passed on to the F2 generation via a mechanism that appears to involved the expression of miRNAs which target the $\beta$-glycan gene (Morgan and Bale, 2011). This result is particularly worthy of note not only because a similar process appears to occur in humans (Oberlander et al., 2008), but because it suggests that at least some behavioral and cognitive sex differences may have and epigenetic rather than a genetic origin. That the effects of prenatal stress may be reversible via post-natal handling (Lemaire et al., 2006) speaks to the possibility that structured behavioral interventions, e.g., (DiCorcia and Tronick, 2011) may have significant translational utility in reducing the incidence of adult mental health issues, many of which show significant associations with maternal stress and depression (Talge et al., 2007; Brand and Brennan, 2009).

\section{EPIGENETIC EFFECTS OF STRESS DURING ADULTHOOD}

The hippocampus has received much attention both from researchers who study stress as well as those who study learning and memory. In animal models it is in fact quite difficult to discern the difference between learning and memory tasks like the Morris water maze or fear conditioning, and acute stressors such as the forced swim test, see for instance (Trollope et al., 2012). As a perusal of the Allen Brain atlas will show, the hippocampus shows high expression levels for a large number of epigenetic enzymes, so it is unsurprising that both stress and memory formation have been shown to utilize epigenetic mechanisms at the level of the hippocampus.

Fear conditioning is associated with a variety of short and long-term epigenetic changes. Miller and Sweatt showed that fear conditioning causes increased expression of the DNA methyltransferases DNMT3A and DNMT3B and that the inhibition of these enzymes impaired the consolidation of fear memories (Miller and Sweatt, 2007). Further, they found that fear conditioning altered DNA methylation on the reelin and PP1 genes, both of which have an influence on memory in other models (Miller and Sweatt, 2007), as well as methylation of the BDNF gene (Lubin et al., 2008). PP1 is notable in that one of its activities seems to be removing phosphorylations from histone $\mathrm{H} 3$ at serine 10 , and that this seems to be the basis for its role in long-term memory (Koshibu et al., 2009, 2011). Another series of studies established a role for histone acetylation in both longterm recall of fear conditioning and spatial memory. These studies 
began with the observation that environmental enrichment (EE), which helped to rescue memory deficits in and inducible neurodegenerative mouse model (CK-p25), also increased levels of histone acetylation in the brain. Utilizing HDAC inhibitors alone the investigators were able to replicate the effects of EE on memory and demonstrate an increase in synapse formation as well (Fischer et al., 2007). A subsequent study established that HDAC2 was the major neuronal class I HDAC and the HDAC responsible for modulating memory and synaptic plasticity, via a surprisingly select number of genes, including glutamate receptor subunits and BDNF (Guan et al., 2009), the later observation, replicating the work of Bredy (Bredy et al., 2007). These findings provide the outlines of a complex set of interactions between memory, stress, or fear, a number of different epigenetic actors and long-term plasticity of the brain and behavior.

With regard to explicit examinations of the effects of stress upon epigenetic modifications in the brain one of the earliest findings was that of Bilang-Bleuel, who found that forced swim stress produced a significant increase in phospho-acetylation of Histone $\mathrm{H} 3$, at serine 10 and lysine 14 (H3S10p-K14ac) respectively, in the dentate gyrus of the hippocampal formation (Bilang-Bleuel et al., 2005). This combination of histone marks is associated with a transcriptionally active chromatin state (Cheung et al., 2000; Clayton et al., 2000), and had been previously observed in the brain after treatment with a variety of neurotransmitter receptor agonists (Crosio et al., 2003). Work building on this initial finding established that a similar induction was produced by novelty stress and that in both cases the phenomenon was $N$-Methyl-D-aspartate (NMDA) receptor dependent, and associated with c-Fos induction in the same cells which showed the H3S10p-K14ac signal (Chandramohan et al., 2007, 2008). Another study demonstrated that inhibitory input from GABAergic neurons acted as a break on the up-regulation of H3S10p-K14ac (Papadopoulos et al., 2011). Given the long association between the actions of glucocorticoid and glutamatergic signaling in the effects of stress on the hippocampal formation, e.g., (McEwen, 1999), it is encouraging that the H3S10p-K14ac story appears to require both actors, though through the novel intermediaries of Elk-1 and MSK1. GR appears to interact directly with these proteins, promoting their phosporylation via NMDA receptor activation of the ERK-MAPK pathway and that this activation plays a role in the formation of the memory of the event (Reul et al., 2009; Gutierrez-Mecinas et al., 2011). Voluntary exercise, which is typically protective against the negative sequelae of stress, actually increases the levels of H3S10p-K14ac after both novelty and swim stress, suggesting that this may be part of an adaptive stress response rather than a pathological one (Collins et al., 2009).

Social defeat stress, which represents one of the stronger models of human depression in terms of ethological and face validity (Nestler and Hyman, 2010), has a clear epigenetic component as well, as was first demonstrated in the Nestler laboratory (Tsankova et al., 2006). They found that chronic social defeat profoundly increased the levels of the repressive histone mark H3 lysine 27 dimethyl at promoter regions of the BDNF gene, while treatment with antidepressants produced and increase in activating marks such as histone $\mathrm{H} 3$ acetylation and histone $\mathrm{H} 3$ lysine four dimethylation (Tsankova et al., 2004, 2006). Subsequent studies found associations between chronic cocaine and social stress and HDAC5 (Renthal et al., 2007), as well as an antidepressant effect of HDAC2 in the social defeat model (Covington et al., 2009), the latter of particular interest given its importance in memory and the effects of EE mentioned above. Chronic social defeat also induced DNMT3a expression in the accumbens, while chronic cocaine reduced it (LaPlant et al., 2010). In the paraventricular nucleus of the hypothalamus resilience to social stress has been found to correlate with the DNA methylation status of the CRH gene (Elliott et al., 2010), further evidence that DNA methylation also plays a role in stress and stress resilience. The Nestler group also found connections between anti-depressant activity, resilience to social defeat and changes in the repressive histone $\mathrm{H} 3$ lysine 9 and 27 methylations in the nucleus accumbens (Wilkinson et al., 2009; Covington et al., 2011). The H3K9 di-or tri-methyl mark has also been shown to change in response to cocaine administration in the accumbens (Maze et al., 2010) and increase in response to acute restraint stress or chronic fluoxetine in the hippocampus (Hunter et al., 2009). The later study also demonstrated stress dependent changes in both the H3K4me3 and H3K27me3 marks. The fact that both cocaine and stress effect the same marks follows from the link between cocaine's reinforcing effects and corticosteroids (Piazza et al., 1991). Thus, interventions that increase levels of $\mathrm{H} 3 \mathrm{~K} 9$ di-or tri-methyl in the limbic system, appear to promote resilience to stress and depression like behavior in animal models. Indeed, the methyl donor SAMe has been shown to have anti-depressant effects in humans (Miller, 2008), though whether this is due to an effect on epigenetic modifications is not yet clear.

The effects of stress on non-coding RNA activity and the regulation of the stress axis by ncRNA in the brain, have received less attention than DNA methylation and histone modification, but the few studies thus far completed demonstrate that the epigenetic actions of RNA are also likely to be a significant part of the effects of stress upon the brain. The GR is the target of a number of miRNAs (Turner et al., 2010). Uchida was the first to observe that the miRNA, miR-18a was involved in region and strain specific regulation of GR expression and stress responsiveness in Fischer 344 rats (Uchida et al., 2008). Another miRNA, miR-124a was soon added to the list of negative regulators of GR expression (Vreugdenhil et al., 2009). Both acute and chronic stress have been shown to regulate the expression of miR-134 and miR-183 in the hippocampus and amygdala and these miRNAs in turn regulate the splicing of acetylcholinesterase, and may thus fine tune the activity of the cholinergic system in response to stress (Meerson et al., 2010). Acute and chronic stress also appear to regulate miR-34 in the amygdala, where it reduces anxiety by reducing the expression of the CRHR1 receptor (Haramati et al., 2011). Acute stress selectively regulates let-7a, miR-9 and miR $26-\mathrm{a} / \mathrm{b}$ in the frontal cortex, but not the hippocampus of mice (Rinaldi et al., 2010). Regionally and temporally specific regulation of miR-186 and miR 709 was found in the hippocampus, prefrontal cortex and cerebellum of rats stressed for either 2 or 4 weeks and miR-186 were found to regulate the expression of the Eps-15 gene (Babenko et al., 2012). Mongrain found that a sleep deprivation stress caused significant changes in the expression 
of 10 miRNAs in the mouse brain, as seven of these did not change in adrenalectomized mice, it is probable they are regulated by corticosteroids (Mongrain et al., 2010). While the relations of whole classes of ncRNA's to stress and the stress axis remain to be explored, it can be said that ncRNA has a clear relation to the epigenetic tuning of the stress response and will likely provide a novel avenue to understanding stress and its associated pathologies.

\section{CONCLUSIONS}

Though the study of the interactions between the stress axis and the epigenome remains in its early stages, its promise is already evident. It is already clear that stressful interactions with the environment induce regionally and developmentally specific changes in behavior and in brain structure and function. It is also apparent that many of these changes are potentially reversible via environmental or pharmacologic interventions.

As most of the studies rehearsed here have focused on regional changes in epigenetic marks, in no small part due to the technical difficulties involved with ChIP in small tissue samples, future studies examining sub-regional differences known to be behaviorally significant, such as comparisons between the accumbens shell and core or the dorsal and ventral hippocampus will be highly important for the integration of epigenetics with existing knowledge of functional neuroanatomy and behavior. A few groups have shown the way in this regard, notably (Roth et al., 2011), who found that chronic psychosocial stress after predator exposure, a model of PTSD, produced a significant increase in DNA methylation of the BDNF gene in the dorsal hippocampus while a decrease was seen in the ventral sub-region. As these two regions are known to be not only functionally distinct, but distinct in terms of gene expression phenotype (Fanselow and Dong, 2010), this finding is of great interest, and points the way for future work on the functional epigenetics of stress.

While it is well established that perinatal insults and abuse and neglect during childhood have an impact on susceptibility to neuropsychiatric disease, and higher order (i.e., non-molecular) epigenetic processes are implicated in that susceptibility. We have only just begun to understand how these influences operate at the level of molecular epigenetics. This is particularly true of the developmental period where many disorders first appear, that is adolescence (Veenema, 2009). To date, no studies of which this author is aware have examined molecular epigenetic mechanisms in the context of adolescent stress, and this is a situation which will hopefully soon be remedied. In addition, studies which examine the interaction of stress in earlier life with behavior during adolescence would be highly desirable.

\section{REFERENCES}

Allis, C. D., Berger, S. L., Cote, J., Dent, S., Jenuwien, T., Kouzarides,

T., Pillus, L., Reinberg, D., Shi,

Y., Shiekhattar, R., Shilatifard,

A., Workman, J., and Zhang, Y.

(2007). New nomenclature for chromatin-modifying enzymes. Cell 131, 633-636.

Allis, C. D., Jenuwein, T., Reinberg, D., and Capparros, M.-L. (2007). Epigenetics, Vol. Cold Spring
Harbor, NY: Cold Spring Harbor

Alt, S. R., Turner, J. D., Klok, M. D., Meijer, O. C., Lakke, E. A., Derijk, R. H., and Muller, C. P. (2010). Differential expression of glucocorticoid receptor transcripts in major depressive disorder is not epigenetically programmed. Psychoneuroendocrinology 35, 544-556.

Babenko, O., Golubov, A., Ilnytskyy, Y., Kovalchuk, I., and Metz, G. Laboratory Press.

While the usual suspects in stress research, GR, BDNF CRH, etc., have received justified attention as actors in the epigenetics of stress, it is evident that these cannot be the only players upon the stage. For example, the mineralocorticoid receptor, which has been implicated in altered histone methylation in the kidney (Zhang et al., 2009), has not been examined in the brain in any such context, despite its role in HPA feedback, hippocampal function and anxiety (Kolber et al., 2008). A benefit, in this regard, of emerging next-generation sequencing technologies is their genome wide reach, attentive researchers will be able to discover entirely new classes of genes mediating the response to stress in various brain regions. Further, we can now look beyond the genes themselves to the other $95 \%$ of the genome, $90 \%$ of which may be actively transcribed ENCODE Project Consortium (2004). This would suggest that the range of potential sites for epigenetic action is an order of magnitude greater than was foreseeable 10 years ago.

For epigenetic research to be translatable, epigenetic pharmacology will have to improve. Though a variety of histone deacetylase inhibitors are available and already approved as drugs for human use, drugs to alter histone methylation are fewer in number, though this situation appears to be changing for the better, e.g., (Spannhoff et al., 2009). As to other histone modifications, most of which have not been examined in the context of stress or mental disorders, still less is known. The various mechanisms and functions of ncRNA are not clear enough as yet for small molecule inhibitors to be examined systematically, though some work has begun with regard to microRNAs (Connelly et al., 2012). It is to be hoped that this foundation will continue to expand so that epigenetic science can fulfill in the clinic the promise it has thus far shown at the bench.

Many open questions remain, particularly with regard to cross talk between epigenetic actors and their interactions with neurotransmitter systems and intracellular signaling cascades. Precisely how epigenetic marks, which have been revealed to be quite dynamic in recent years, maintain stability and specificity over time is another question that deserves exploration. As next-generation sequencing technology improves and cellular resolution epigenetic analyses become more practicable our understanding will become more complex and the potential for novel therapeutic interventions in stress related diseases will be realized.

\section{ACKNOWLEDGMENTS}

Dr. Hunter was supported by the Betz Family NARSAD Young investigator award, the Hope for Depression Research Foundation and NIMH MH 41256.

A. (2012). Genomic and epigenomic responses to chronic stress involve miRNA-mediated programming. PLoS One 7:e29441. doi: 10.1371/journal.pone.0029441

Balakrishnan, L., and Milavetz, B. (2010). Decoding the histone H4 lysine 20 methylation mark. Crit. Rev. Biochem. Mol. Biol. 45, 440-452.

Banerjee, T., and Chakravarti, D. (2011). A peek into the complex realm of histone phosphorylation. Mol. Cell. Biol. 31, 4858-4873.

Bilang-Bleuel, A., Ulbricht, S., Chandramohan, Y., De Carli, S., Droste, S. K., and Reul, J. M. (2005). Psychological stress increases histone H3 phosphorylation in adult dentate gyrus granule neurons: involvement in a glucocorticoid receptor-dependent behavioural response. Eur. J. Neurosci. 22, 1691-1700. 
Brand, S. R., and Brennan, P. A. (2009). Impact of antenatal and postpartum maternal mental illness: how are the children? Clin. Obstet. Gynecol. 52, 441-455.

Bredy, T. W., Wu, H., Crego, C., Zellhoefer, J., Sun, Y. E., and Barad, M. (2007). Histone modifications around individual BDNF gene promoters in prefrontal cortex are associated with extinction of conditioned fear. Learn. Mem. 14, 268-276.

Cervoni, N., and Szyf, M. (2001). Demethylase activity is directed by histone acetylation. J. Biol. Chem. 276, 40778-40787.

Champagne, F. A., Francis, D. D., Mar, A., and Meaney, M. J. (2003). Variations in maternal care in the rat as a mediating influence for the effects of environment on development. Physiol. Behav. 79, 359-371.

Chandramohan, Y., Droste, S. K., Arthur, J. S., and Reul, J. M. (2008). The forced swimminginduced behavioural immobility response involves histone $\mathrm{H} 3$ phospho-acetylation and c-Fos induction in dentate gyrus granule neurons via activation of the $\mathrm{N}$-methyl-D-aspartate/extracellular signal-regulated kinase/mitogenand stress-activated kinase signalling pathway. Eur. J. Neurosci. 27, 2701-2713.

Chandramohan, Y., Droste, S. K., and Reul, J. M. (2007). Novelty stress induces phospho-acetylation of histone $\mathrm{H} 3$ in rat dentate gyrus granule neurons through coincident signalling via the $\mathrm{N}$-methyl-D-aspartate receptor and the glucocorticoid receptor: relevance for $\mathrm{c}$-fos induction. J. Neurochem. 101, 815-828.

Chen, W. G., Chang, Q., Lin, Y., Meissner, A., West, A. E., Griffith, E. C., Jaenisch, R., and Greenberg, M. E. (2003). Derepression of BDNF transcription involves calciumdependent phosphorylation of MeCP2. Science 302, 885-889.

Cheung, P., Tanner, K. G., Cheung, W. L., Sassone-Corsi, P., Denu, J. M., and Allis, C. D. (2000). Synergistic coupling of histone $\mathrm{H} 3$ phosphorylation and acetylation in response to epidermal growth factor stimulation. Mol. Cell 5, 905-915.

Clayton, A. L., Rose, S., Barratt, M. J., and Mahadevan, L. C. (2000). Phosphoacetylation of histone $\mathrm{H} 3$ on c-fos- and c-jun-associated nucleosomes upon gene activation. EMBO J. 19, 3714-3726.

Coe, C. L., Kramer, M., Czeh, B., Gould, E., Reeves, A. J., Kirschbaum, C., and Fuchs, E. (2003). Prenatal stress diminishes neurogenesis in the dentate gyrus of juvenile rhesus monkeys. Biol. Psychiatry 54, 1025-1034.

Collins, A., Hill, L. E., Chandramohan, Y., Whitcomb, D., Droste, S. K., and Reul, J. M. (2009). Exercise improves cognitive responses to psychological stress through enhancement of epigenetic mechanisms and gene expression in the dentate gyrus. PLoS One 4:e4330. doi: 10.1371/journal.pone.0004330

Connelly, C. M., Thomas, M., and Deiters, A. (2012). Highthroughput luciferase reporter assay for small-molecule inhibitors of microRNA function. J. Biomol. Screen. [Epub ahead of print].

Covington, H. E. 3rd., Maze, I., LaPlant, Q. C., Vialou, V. F., Ohnishi, Y. N., Berton, O., Fass, D. M., Renthal, W., Rush, A. J. 3rd., Wu, E. Y., Ghose, S., Krishnan, V., Russo, S. J., Tamminga, C., Haggarty, S. J., and Nestler, E. J. (2009). Antidepressant actions of histone deacetylase inhibitors. J. Neurosci. 29, 11451-11460.

Covington, H. E. 3rd., Maze, I., Sun, H., Bomze, H. M., DeMaio, K. D., Wu, E. Y., Dietz, D. M., Lobo, M. K., Ghose, S., Mouzon, E., Neve, R. L., Tamminga, C. A., and Nestler, E. J. (2011). A role for repressive histone methylation in cocaine-induced vulnerability to stress. Neuron 71, 656-670.

Crosio, C., Heitz, E., Allis, C. D., Borrelli, E., and Sassone-Corsi, P. (2003). Chromatin remodeling and neuronal response: multiple signaling pathways induce specific histone H3 modifications and early gene expression in hippocampal neurons. J. Cell Sci. 116, 4905-4914.

DiCorcia, J. A., and Tronick, E. (2011). Quotidian resilience: exploring mechanisms that drive resilience from a perspective of everyday stress and coping. Neurosci. Biobehav. Rev. 35, 1593-1602.

ENCODE Project Consortium. (2004). The ENCODE (ENCyclopedia Of DNA Elements) Project. Science 306, 636-640.

Elliott, E., Ezra-Nevo, G., Regev, L., Neufeld-Cohen, A., and Chen, A. (2010). Resilience to social stress coincides with functional DNA methylation of the Crf gene in adult mice. Nat. Neurosci. 13, 1351-1353.

Esteller, M. (2011). Non-coding RNAs in human disease. Nat. Rev. Genet. $12,861-874$.

Fanselow, M. S., and Dong, H. W. (2010). Are the dorsal and ventral hippocampus functionally distinct structures? Neuron 65, 7-19.
Fischer, A., Sananbenesi, F., Wang, X., Dobbin, M., and Tsai, L. H. (2007). Recovery of learning and memory is associated with chromatin remodelling. Nature 447, 178-182.

Francis, D., Diorio, J., Liu, D., and Meaney, M. J. (1999). Nongenomic transmission across generations of maternal behavior and stress responses in the rat. Science 286, 1155-1158.

Francis, D. D., and Meaney, M. J. (1999). Maternal care and the development of stress responses. Curr. Opin. Neurobiol. 9, 128-134.

Franklin, T. B., Russig, H., Weiss, I C., Graff, J., Linder, N., Michalon, A., Vizi, S., and Mansuy, I. M. (2010). Epigenetic transmission of the impact of early stress across generations. Biol. Psychiatry 68, 408-415.

Fujioka, A., Fujioka, T., Ishida, Y., Maekawa, T., and Nakamura, S. (2006). Differential effects of prenatal stress on the morphological maturation of hippocampal neurons. Neuroscience 141, 907-915.

Fujioka, T., Fujioka, A., Tan, N., Chowdhury, G. M., Mouri, H., Sakata, Y., and Nakamura, S. (2001). Mild prenatal stress enhances learning performance in the non-adopted rat offspring. Neuroscience 103, 301-307.

Fujioka, T., Sakata, Y., Yamaguchi, K., Shibasaki, T., Kato, H., and Nakamura, S. (1999). The effects of prenatal stress on the development of hypothalamic paraventricular neurons in fetal rats. Neuroscience 92, 1079-1088.

Guan, J. S., Haggarty, S. J., Giacometti, E., Dannenberg, J. H., Joseph, N., Gao, J., Nieland, T. J., Zhou, Y., Wang, X., Mazitschek, R., Bradner, J. E., DePinho, R. A., Jaenisch, R., and Tsai, L. H. (2009). HDAC2 negatively regulates memory formation and synaptic plasticity. Nature 459 , 55-60.

Gutierrez-Mecinas, M., Trollope, A. F., Collins, A., Morfett, H., Hesketh, S. A., Kersante, F., and Reul, J. M. (2011). Long-lasting behavioral responses to stress involve a direct interaction of glucocorticoid receptors with ERK1/2-MSK1-Elk-1 signaling. Proc. Natl. Acad. Sci. U.S.A. 108, 13806-13811.

Haramati, S., Navon, I., Issler, O., Ezra-Nevo, G., Gil, S., Zwang, R., Hornstein, E., and Chen, A. (2011). MicroRNA as repressors of stress-induced anxiety: the case of amygdalar miR-34. J. Neurosci. 31, 14191-14203.

Hunter, R. G., McCarthy, K. J., Milne, T. A., Pfaff, D. W., and McEwen, B.
S. (2009). Regulation of hippocampal H3 histone methylation by acute and chronic stress. Proc. Natl. Acad. Sci. U.S.A. 106, 20912-20917.

Illingworth, R. S., and Bird, A. P. (2009). CpG islands-'a rough guide. FEBS Lett. 583, 1713-1720.

Jenuwein, T., and Allis, C. D. (2001). Translating the histone code. Science 293, 1074-1080.

Jiang, Y., Langley, B., Lubin, F. D., Renthal, W., Wood, M. A., Yasui, D. H., Kumar, A., Nestler, E. J., Akbarian, S., and Beckel-Mitchener, A. C. (2008). Epigenetics in the nervous system. J. Neurosci. 28, 11753-11759.

Kolber, B. J., Wieczorek, L., and Muglia, L. J. (2008). Hypothalamicpituitary-adrenal axis dysregulation and behavioral analysis of mouse mutants with altered glucocorticoid or mineralocorticoid receptor function. Stress 11, 321-338.

Koshibu, K., Graff, J., and Mansuy, I. M. (2011). Nuclear protein phosphatase-1, an epigenetic regulator of fear memory and amygdala long-term potentiation. Neuroscience 173, 30-36.

Koshibu, K., Graff, J., Beullens, M., Heitz, F. D., Berchtold, D., Russig, H., Farinelli, M., Bollen, M., and Mansuy, I. M. (2009). Protein phosphatase 1 regulates the histone code for long-term memory. J. Neurosci. 29, 13079-13089.

Kouzarides, T. (2007). Chromatin modifications and their function. Cell 128, 693-705.

Kriaucionis, S., and Bird, A. (2003). DNA methylation and Rett syndrome. Hum. Mol. Genet. 12, R221-R227.

Kriaucionis, S., and Heintz, N. (2009). The nuclear DNA base 5-hydroxymethylcytosine is present in Purkinje neurons and the brain. Science 324, 929-930.

LaPlant, Q., Vialou, V., Covington, H. E. 3rd., Dumitriu, D., Feng, J., Warren, B. L., Maze, I., Dietz, D. M., Watts, E. L., Iniguez, S. D., Koo, J. W., Mouzon, E., Renthal, W. Hollis, F., Wang, H., Noonan, M. A., Ren, Y., Eisch, A. J., Bolanos, C. A., Kabbaj, M., Xiao, G., Neve, R. L., Hurd, Y. L., Oosting, R. S., Fan, G., Morrison, J. H., and Nestler, E. J. (2010). Dnmt3a regulates emotional behavior and spine plasticity in the nucleus accumbens. Nat. Neurosci. 13, 1137-1143.

Lemaire, V., Koehl, M., Le Moal, M., and Abrous, D. N. (2000). Prenatal stress produces learning deficits associated with an inhibition of neurogenesis in the hippocampus. Proc. Natl. Acad. Sci. U.S.A. 97, 11032-11037. 
Lemaire, V., Lamarque, S., Le Moal, M., Piazza, P. V., and Abrous, D. N. (2006). Postnatal stimulation of the pups counteracts prenatal stress-induced deficits in hippocampal neurogenesis. Biol. Psychiatry 59, 786-792.

Liu, D., Diorio, J., Tannenbaum, B., Caldji, C., Francis, D., Freedman, A., Sharma, S., Pearson, D., Plotsky, P. M., and Meaney, M. J. (1997). Maternal care, hippocampal glucocorticoid receptors, and hypothalamic-pituitary-adrenal responses to stress. Science 277, 1659-1662.

Lubin, F. D., Roth, T. L., and Sweatt, J. D. (2008). Epigenetic regulation of BDNF gene transcription in the consolidation of fear memory. J. Neurosci. 28, 10576-10586.

Martinowich, K., Hattori, D., Wu, H., Fouse, S., He, F., Hu, Y., Fan, G., and Sun, Y. E. (2003). DNA methylation-related chromatin remodeling in activity-dependent BDNF gene regulation. Science 302, 890-893.

Maze, I., Covington, H. E. 3rd., Dietz, D. M., LaPlant, Q., Renthal, W., Russo, S. J., Mechanic, M., Mouzon, E., Neve, R. L., Haggarty, S. J., Ren, Y., Sampath, S. C., Hurd, Y. L., Greengard, P., Tarakhovsky, A., Schaefer, A., and Nestler, E. J. (2010). Essential role of the histone methyltransferase G9a in cocaine-induced plasticity. Science $327,213-216$.

McEwen, B. S. (1999). Stress and hippocampal plasticity. Annu. Rev. Neurosci. 22, 105-122.

McGowan, P. O., Sasaki, A., D’Alessio, A. C., Dymov, S., Labonte, B., Szyf, M., Turecki, G., and Meaney, M. J. (2009). Epigenetic regulation of the glucocorticoid receptor in human brain associates with childhood abuse. Nat. Neurosci. 12, 342-348.

Meerson, A., Cacheaux, L., Goosens, K. A., Sapolsky, R. M., Soreq, H., and Kaufer, D. (2010). Changes in brain MicroRNAs contribute to cholinergic stress reactions. J. Mol. Neurosci. $40,47-55$.

Miller, A. L. (2008). The methylation, neurotransmitter, and antioxidant connections between folate and depression. Altern. Med. Rev. 13, 216-226.

Miller, C. A., and Sweatt, J. D. (2007). Covalent modification of DNA regulates memory formation. Neuron $53,857-869$.

Mongrain, V., Hernandez, S. A., Pradervand, S., Dorsaz, S., Curie, T., Hagiwara, G., Gip, P., Heller, H. C., and Franken, P. (2010). Separating the contribution of glucocorticoids and wakefulness to the molecular and electrophysiological correlates of sleep homeostasis. Sleep 33, 1147-1157.

Morgan, C. P., and Bale, T. L. (2011). Early prenatal stress epigenetically programs dysmasculinization in second-generation offspring via the paternal lineage. J. Neurosci. 31, 11748-11755.

Mueller, B. R., and Bale, T. L. (2008). Sex-specific programming of offspring emotionality after stress early in pregnancy. J. Neurosci. 28, 9055-9065.

Murgatroyd, C., Patchev, A. V., Wu, Y., Micale, V., Bockmuhl, Y., Fischer, D., Holsboer, F., Wotjak, C. T., Almeida, O. F., and Spengler, D. (2009). Dynamic DNA methylation programs persistent adverse effects of early-life stress. Nat. Neurosci. 12, 1559-1566.

Nestler, E. J., and Hyman, S. E. (2010). Animal models of neuropsychiatric disorders. Nat. Neurosci. 13, 1161-1169.

Oberlander, T. F., Weinberg, J., Papsdorf, M., Grunau, R., Misri, S., and Devlin, A. M. (2008). Prenatal exposure to maternal depression, neonatal methylation of human glucocorticoid receptor gene (NR3C1) and infant cortisol stress responses. Epigenetics 3, 97-106.

Papadopoulos, A., Chandramohan, Y., Collins, A., Droste, S. K., Nutt, D. J., and Reul, J. M. (2011). GABAergic control of novelty stress-responsive epigenetic and gene expression mechanisms in the rat dentate gyrus. Eur. Neuropsychopharmacol. 21, 316-324.

Piazza, P. V., Maccari, S., Deminiere, J. M., Le Moal, M., Mormede, P., and Simon, H. (1991). Corticosterone levels determine individual vulnerability to amphetamine selfadministration. Proc. Natl. Acad. Sci. U.S.A. 88, 2088-2092.

Renthal, W., Maze, I., Krishnan, V., Covington, H. E. 3rd., Xiao, G., Kumar, A., Russo, S. J., Graham, A., Tsankova, N., Kippin, T. E., Kerstetter, K. A., Neve, R. L., Haggarty, S. J., McKinsey, T. A., Bassel-Duby, R., Olson, E. N., and Nestler, E. J. (2007). Histone deacetylase 5 epigenetically controls behavioral adaptations to chronic emotional stimuli. Neuron 56, 517-529.

Reul, J. M., Hesketh, S. A., Collins, A., and Mecinas, M. G. (2009). Epigenetic mechanisms in the dentate gyrus act as a molecular switch in hippocampus-associated memory formation. Epigenetics 4, 434-439.
Rinaldi, A., Vincenti, S., De Vito, F., Bozzoni, I., Oliverio, A., Presutti, C., Fragapane, P., and Mele, A. (2010). Stress induces region specific alterations in microRNAs expression in mice. Behav. Brain Res. 208, 265-269.

Roth, T. L., Lubin, F. D., Funk, A. J., and Sweatt, J. D. (2009). Lasting epigenetic influence of early-life adversity on the BDNF gene. Biol. Psychiatry $65,760-769$.

Roth, T. L., Zoladz, P. R., Sweatt, J. D., and Diamond, D. M. (2011) Epigenetic modification of hippocampal Bdnf DNA in adult rats in an animal model of post-traumatic stress disorder. J. Psychiatr. Res. 45, 919-926.

Ruthenburg, A. J., Allis, C. D., and Wysocka, J. (2007a). Methylation of lysine 4 on histone $\mathrm{H} 3$, intricacy of writing and reading a single epigenetic mark. Mol. Cell 25, 15-30.

Ruthenburg, A. J., Li, H., Patel, D. J., and Allis, C. D. (2007b). Multivalent engagement of chromatin modifications by linked binding modules. Nat. Rev. Mol. Cell Biol. 8, 983-994.

Schmitt, M., and Matthies, H. (1979). Biochemical studies on histones of the central nervous system. III. Incorporation of [14C]-acetate into the histones of different rat brain regions during a learning experiment. Acta Biol. Med. Ger. 38, 683-689.

Spannhoff, A., Hauser, A. T., Heinke, R., Sippl, W., and Jung, M. (2009). The emerging therapeutic potential of histone methyltransferase and demethylase inhibitors. ChemMedChem 4, 1568-1582.

Talge, N. M., Neal, C., and Glover, V. (2007). Antenatal maternal stress and long-term effects on child neurodevelopment: how and why? J. Child Psychol. Psychiatry 48, 245-261.

Trollope, A. F., Gutierrez-Mecinas, M., Mifsud, K. R., Collins, A., Saunderson, E. A., and Reul, J. M. (2012). Stress, epigenetic control of gene expression and memory formation. Exp. Neurol. 233, 3-11.

Tsankova, N. M., Berton, O., Renthal, W., Kumar, A., Neve, R. L., and Nestler, E. J. (2006). Sustained hippocampal chromatin regulation in a mouse model of depression and antidepressant action. Nat. Neurosci. 9, 519-525.

Tsankova, N. M., Kumar, A., and Nestler, E. J. (2004). Histone modifications at gene promoter regions in rat hippocampus after acute and chronic electroconvulsive seizures. J. Neurosci. 24, 5603-5610.

Turner, J. D., Alt, S. R., Cao, L., Vernocchi, S., Trifonova, S., Battello, N., and Muller, C. P. (2010). Transcriptional control of the glucocorticoid receptor: CpG islands, epigenetics and more. Biochem. Pharmacol. 80, 1860-1868.

Turner, J. D., and Muller, C. P. (2005). Structure of the glucocorticoid receptor (NR3C1) gene 5' untranslated region: identification, and tissue distribution of multiple new human exon 1. J. Mol. Endocrinol. 35, 283-292.

Uchida, S., Nishida, A., Hara, K., Kamemoto, T., Suetsugi, M., Fujimoto, M., Watanuki, T., Wakabayashi, Y., Otsuki, K. McEwen, B. S., and Watanabe, Y. (2008). Characterization of the vulnerability to repeated stress in Fischer 344 rats: possible involvement of microRNA-mediated down-regulation of the glucocorticoid receptor. Eur. J. Neurosci. 27, 2250-2261.

Veenema, A. H. (2009). Early life stress, the development of aggression and neuroendocrine and neurobiological correlates: what can we learn from animal models? Front. Neuroendocrinol. 30, 497-518.

Vreugdenhil, E., Verissimo, C. S., Mariman, R., Kamphorst, J. T., Barbosa, J. S., Zweers, T., Champagne, D. L., Schouten, T., Meijer, O. C., de Kloet, E. R., and Fitzsimons, C. P. (2009). MicroRNA 18 and 124a down-regulate the glucocorticoid receptor: implications for glucocorticoid responsiveness in the brain. Endocrinology 150, 2220-2228.

Waddington, C. H. (1942). The epigenotype. Endeavour 1, 18-20.

Weaver, I. C., Cervoni, N., Champagne, F. A., D'Alessio, A. C., Sharma, S., Seckl, J. R., Dymov, S., Szyf, M., and Meaney, M. J. (2004) Epigenetic programming by maternal behavior. Nat. Neurosci. 7 , 847-854.

Weaver, I. C., D'Alessio, A. C., Brown, S. E., Hellstrom, I. C., Dymov, S. Sharma, S., Szyf, M., and Meaney, M. J. (2007). The transcription factor nerve growth factor-inducible protein a mediates epigenetic programming: altering epigenetic marks by immediate-early genes. J. Neurosci. 27, 1756-1768.

Wilkinson, M. B., Xiao, G., Kumar, A., LaPlant, Q., Renthal, W., Sikder, D., Kodadek, T. J., and Nestler, E. J. (2009). Imipramine treatment and resiliency exhibit 
similar chromatin regulation in the mouse nucleus accumbens in depression models. J. Neurosci. 29, 7820-7832.

Wu, H., and Zhang, Y. (2011). Mechanisms and functions of Tet protein-mediated 5-methylcytosine oxidation. Genes Dev. 25, 2436-2452.

Zhang, D., Yu, Z. Y., Cruz, P., Kong, Q., Li, S., and Kone, B. C. (2009).
Epigenetics and the control of epithelial sodium channel expression in collecting duct. Kidney Int. 75, 260-267.

Conflict of Interest Statement: The author declares that the research was conducted in the absence of any commercial or financial relationships that could be construed as a potential conflict of interest.

Received: 22 February 2012; paper pending published: 18 March 2012; accepted: 02 April 2012; published online: 19 April 2012.

Citation: Hunter RG (2012) Epigenetic effects of stress and corticosteroids in the brain. Front. Cell. Neurosci. 6:18. doi: 10.3389/fncel.2012.00018

Copyright (c) 2012 Hunter. This is an open-access article distributed under the terms of the Creative Commons Attribution Non Commercial License, which permits non-commercial use, distribution, and reproduction in other forums, provided the original authors and source are credited. 